\title{
Normal values of corneal optical densitometry using pentacam scheimpflug camera
}

\begin{abstract}
Purpose: The purpose of the study was to illustrate the range of normal values of corneal densitometry using Pentacam Scheimpflug camera.

Methodology: Prospective study was conducted at tertiary care Amanat eye hospital. 490 eyes of 490 participants of different age groups were added. All scans were performed in diagnostics room with uniform ambient light, performed by trained ophthalmic technologist. All participants were Pakistani of different ethnic groups. Only one eye of each participant was included to control biasness. T test, One-way ANOVA, pearson correlation coefficient and linear regression model tests were applied for analysis.
\end{abstract}

Results: 490 eyes; 247 right eyes and 243 left eyes were analyzed. Mean age was $41.7 \pm 15.27$ years (range 20-81 years) with $48.4 \%$ male and $51.6 \%$ females. based on corneal depth; highest backward scattering of light was observed in anterior $(120 \mu \mathrm{m})$ layer $(20.6 \pm 8.52$ GSU) than central and posterior layers 13.6 $\pm 5.17 \mathrm{GSU}$ and 11.7 \pm 3.99 GSU respectively. The difference was statistically significant among layers with $\mathrm{p}<0.001$. Based on corneal surface, minimum backscattering was noted in central $0-6 \mathrm{~mm}$ zone which increases from central to limbal zone; $0-2 \mathrm{~mm}$ zone was $13.2 \pm 3.81 \mathrm{GSU}, 2-6 \mathrm{~mm}$ zone was $12.6 \pm 3.68 \mathrm{GSU}$, 6-10mm zone was $16.0 \pm 8.90 \mathrm{GSU}$ and $10-12 \mathrm{~mm}$ zone was $22.1 \pm 8.26 \mathrm{GSU}$. The difference was statistically significant with $\mathrm{p}<0.001$. Significant correlation of corneal densitometry and age was observed $\mathrm{r}=0.677, \mathrm{p}<0.001$.

Conclusion: Objective assessment of corneal densitometry can be made with Pentacam Scheimpflug. Normative values of corneal density may be used in routine clinical practice and provided a reference for future research.

Keywords: corneal densitometry, pentacam scheimpflug, corneal health, corneal transparency
Volume 5 Issue I - 2016

\author{
Aamir Asrar,' Bisma Ikram, ${ }^{2}$ Hina Khan, ${ }^{2}$ \\ Maha Asrar ${ }^{3}$ \\ 'Department of Ophthalmology, Amanat Eye Hospital, Pakistan \\ ${ }^{2}$ Department of Ophthalmic Diagnostic, Amanat Eye Hospital, \\ Pakistan \\ ${ }^{3}$ Medical Student, Shifa College of Medicine, Pakistan
}

Correspondence: Hina Khan, Consultant Ophthalmologist, Head of Ophthalmic Diagnostic Department, Amanat Eye Hospital, Islamabad, Pakistan, Tel 92322585 I I I3, Email drhina@amanathospital.com

Received:September 26, 2016 | Published: September 30, 2016

\section{Introduction}

Cornea is unique to its transparency. It has Peculiar feature of transmitting almost all the light passing through it. Corneal clarity dwindles with surgical or pathological insults i.e. infections, corneal dystrophies and degenerations. ${ }^{1}$ This induced corneal haze impedes the light rays to pass which results in backward scattering of light. ${ }^{2}$ Maintaining regular surveillance over resulting corneal haze is vital element of ophthalmological examination. Previously, the optical quality of cornea was assessed and monitored by standard slit lamp examination i.e. light scattering back to observer and extent of severity was graded subjectively. ${ }^{3-5}$ This subjective evaluation tends to vary between observers. Commencement of objective method was imperative to produce more reliable and reproducible results.

Pentacam Scheimpflug camera is noninvasive system that facilitates analysis of anterior segment and backscattered light simultaneously with automated detection of correct focus and alignment. ${ }^{6,7}$ With the generation of colored maps of cornea; topography, pachymetry, anterior chamber depth and densitometry is more simplified than ever. It is now possible to generate and reproduce maps on amount of backscattered light, called corneal densitometry map. With such technique, high amount of backward scattering of light was discerned in corneas that were considered clinically clear. ${ }^{8}$ Based on above, current study aimed to determine the normal values of corneal densitometry using Pentacam Scheimpflug Camera, measurements taken from large group of Asian participants of different age groups.

\section{Methodology}

Prospective cross sectional study was conducted at tertiary care Amanat eye hospital Rawalpindi. 490 eyes of 490 participants were enrolled from hospital population during June to August 2016. Consecutive sampling technique was used to recruit the participants. The study was accordance to the tenets of Declaration of Helsinki. Ethical review board of hospital approved the study protocols. All the participants were comprehended about nature and purpose of this study and consent was sought before Pentacam examination. Participants aged above 20 years and without any history of corneal pathologies were included in the study. Patients who reported any history of cornea or intraocular surgery such as refractive surgery, CXL, phacoemulsification, vitrectomy etc were excluded. Conditions like corneal dystrophies, keratoconus, trauma or infections were also considered as exclusion criteria. Conditions associated with age like peripheral limbal corneal degeneration were not considered as exclusion criteria. Patients having systematic medication known to induce corneal changes were also excluded. Only one eye of all participants was taken into account to avoid artificially reduced dispersion measurements, as the both eyes of a patient correlate well. Data from Right eye of first 50\% participants in all age groups were 
taken and left eye for rest for the participants were included to acquire data.

\section{Measurement technique}

All the scans were performed in diagnostics room (windowless) with uniform ambient light performed by trained ophthalmic technologist. Pentacam is programmed to automatically locate corneal apex and takes 25 images over different meridians of cornea with uniform blue light source. Grayscale unit (GSU) is used to indicate the densitometry output; value ranges from 0 (minimum light scattering) to 100 (maximum light scattering). The software is provided with coded instruction to subdivide the cornea into 4 concentric zones areas; central zone from $0-2 \mathrm{~mm}$; second zone extending from 2 to $6 \mathrm{~mm}$; next from 6 to $10 \mathrm{~mm}$ and fourth from $10-12 \mathrm{~mm}$ zones. Corneal depth is divided as anterior layer $(120 \mu \mathrm{m})$, central layer and posterior layers $(60 \mu \mathrm{m})$. The central layer has no fixed thickness; it is measured by subtraction of anterior and posterior layers thickness from overall corneal thickness. The software provides details analysis of cornea depending upon area and corneal depth.

\section{Statistical analysis}

Data was organized and analyzed by Statistical Package for the Social Sciences (SPSS version 22) and Microsoft Excel 2010. T test, One-way ANOVA, pearson correlation coefficient and linear regression model tests were applied for data analysis with $95 \%$ confidence interval and level of significance $(\alpha)=0.05$.

\section{Results}

490 eyes of 490 healthy participants; 247 right eyes and 243 left eyes were included. The mean age was $41.7 \pm 15.27$ years (range $20-81$ years); $48.4 \%$ male and $51.6 \%$ females (Figure 1). Mean densitometry of the entire corneal surface was $15.3 \pm 5.79$ GSU. The mean corneal densitometry of $0-2 \mathrm{~mm}$ zone was $13.2 \pm 3.81 \mathrm{GSU}, 2-6 \mathrm{~mm}$ zone was $12.6 \pm 3.68 \mathrm{GSU}, 6-10 \mathrm{~mm}$ zone was $16.0 \pm 8.90 \mathrm{GSU}$ and $10-12 \mathrm{~mm}$ zone was $22.1 \pm 8.26$ GSU. The mean difference between $0-2 \mathrm{~mm}$ and $2-6 \mathrm{~mm}$ zones was significant with $\mathrm{p}=0.015$. However, values for all other zones were highly significant with $\mathrm{p}<0.001$ (One-way ANOVA) (Figures 2-6).

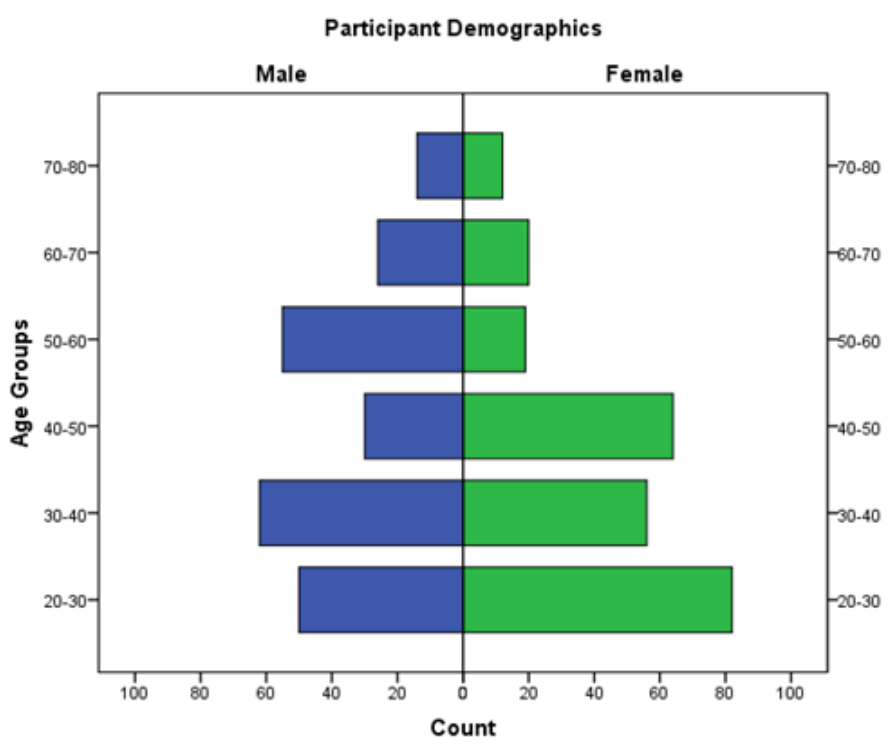

Figure I Participants Demographics;Age distribution; Gender distribution; Count.

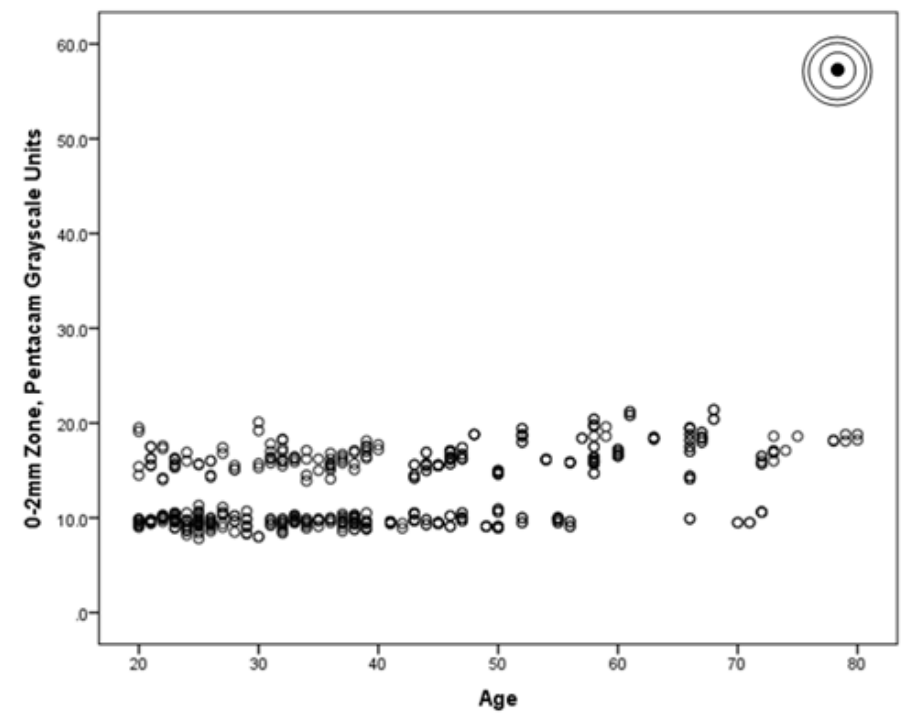

Figure 2 Linear Regression model; corneal densitometry; 0-2 mm zone plotted against age. 


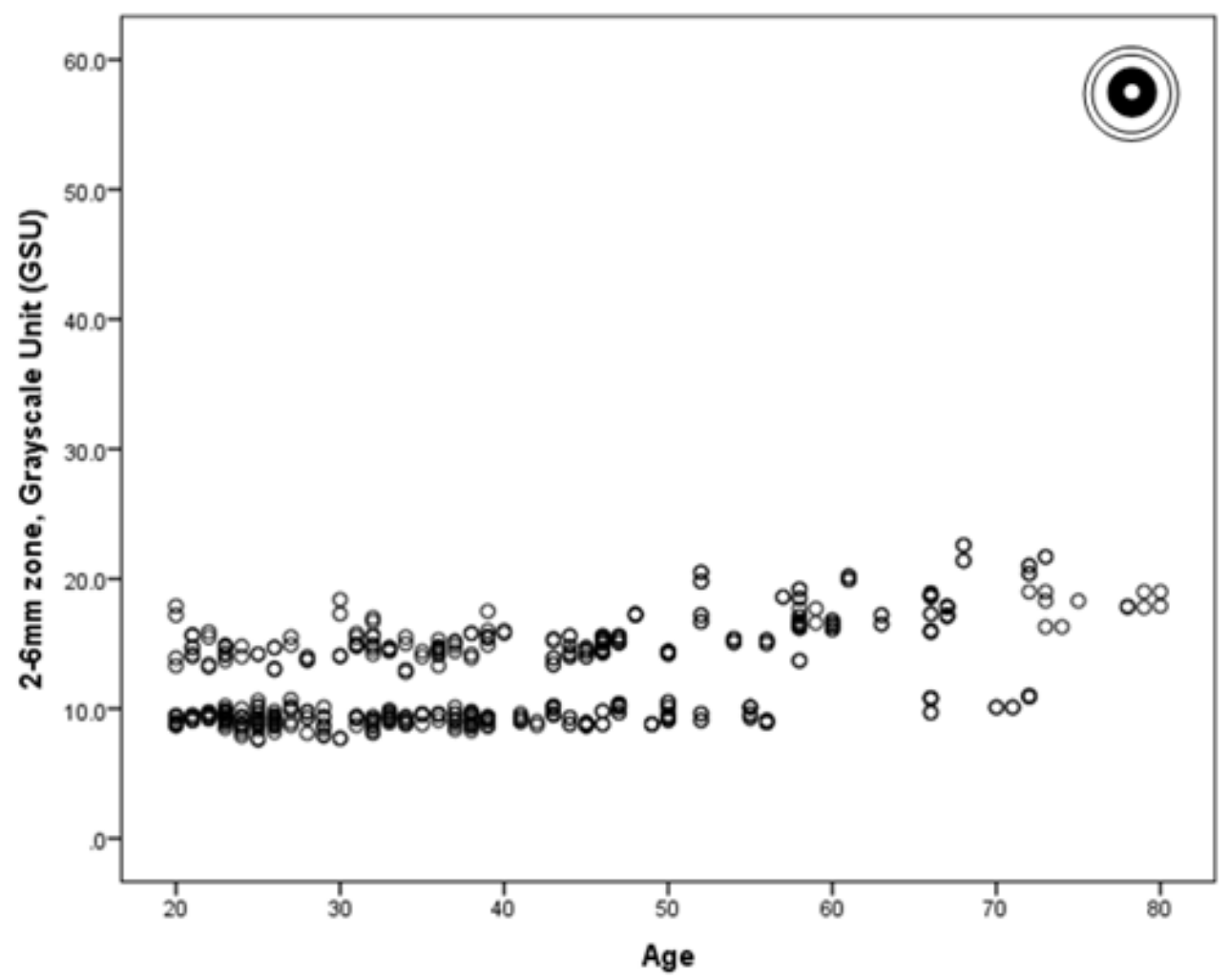

Figure 3 Linear Regression model; corneal densitometry; 2-6mm zone plotted against age.

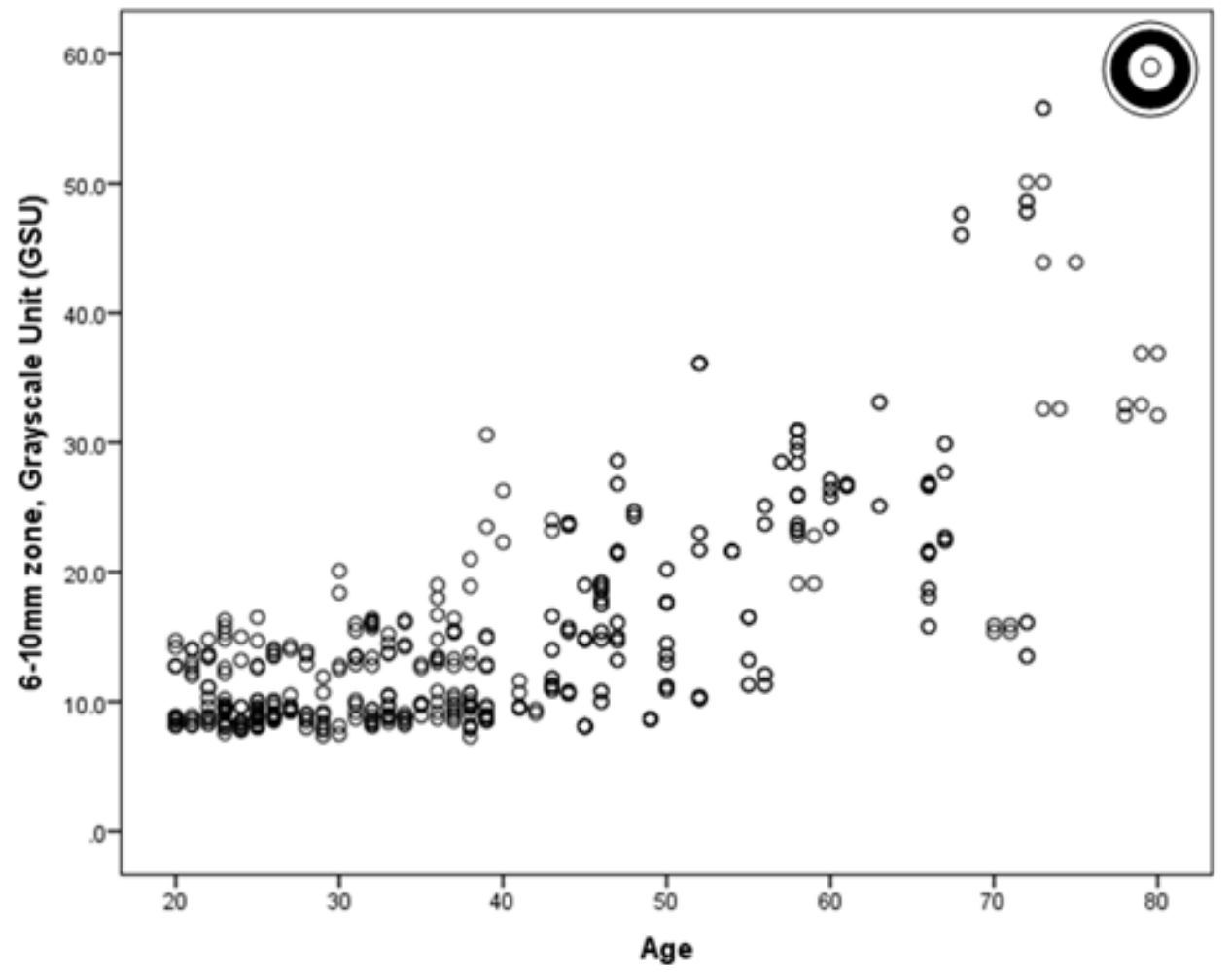

Figure 4 Linear Regression model; corneal densitometry; 6-10 mm zone plotted against age. 


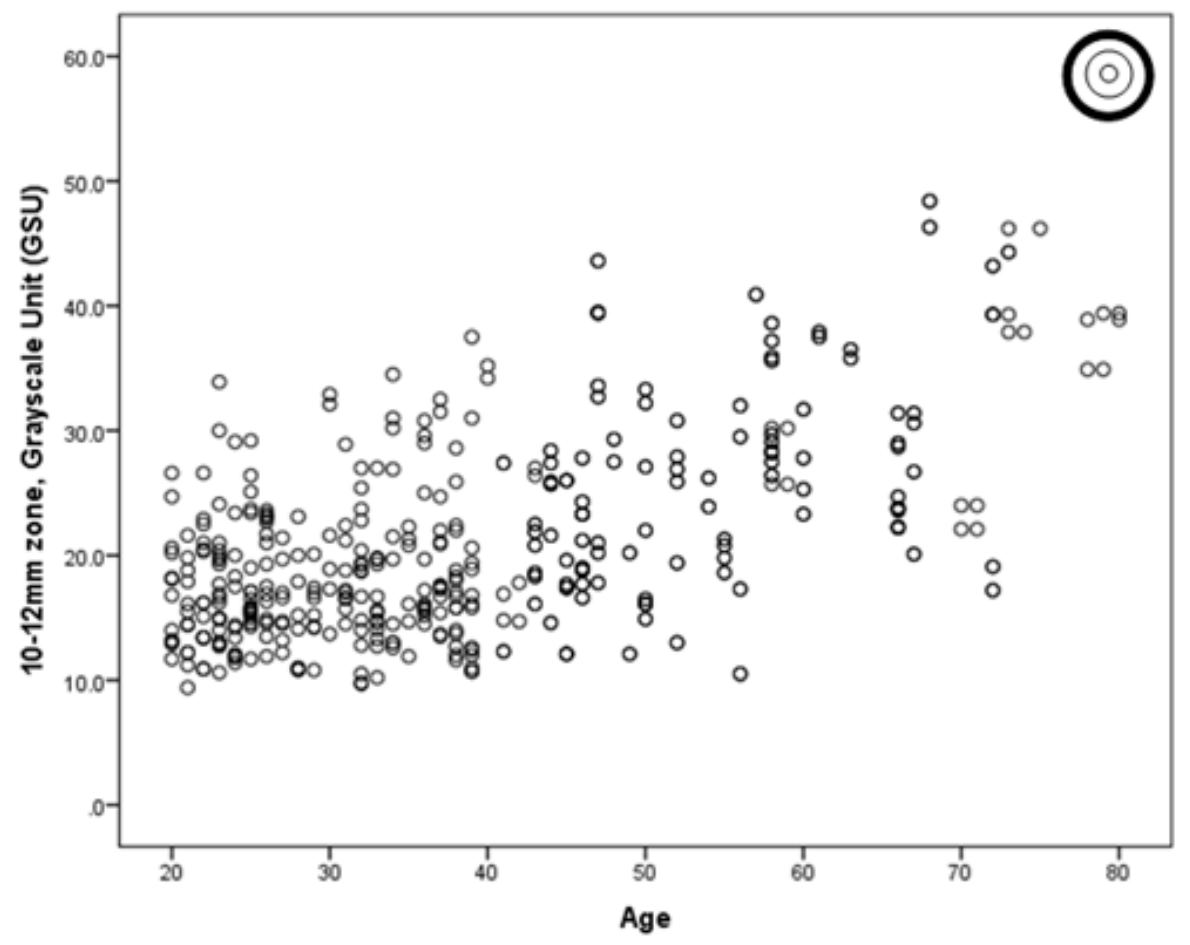

Figure 5 Linear Regression model; corneal densitometry; 10-12mm zone plotted against age.

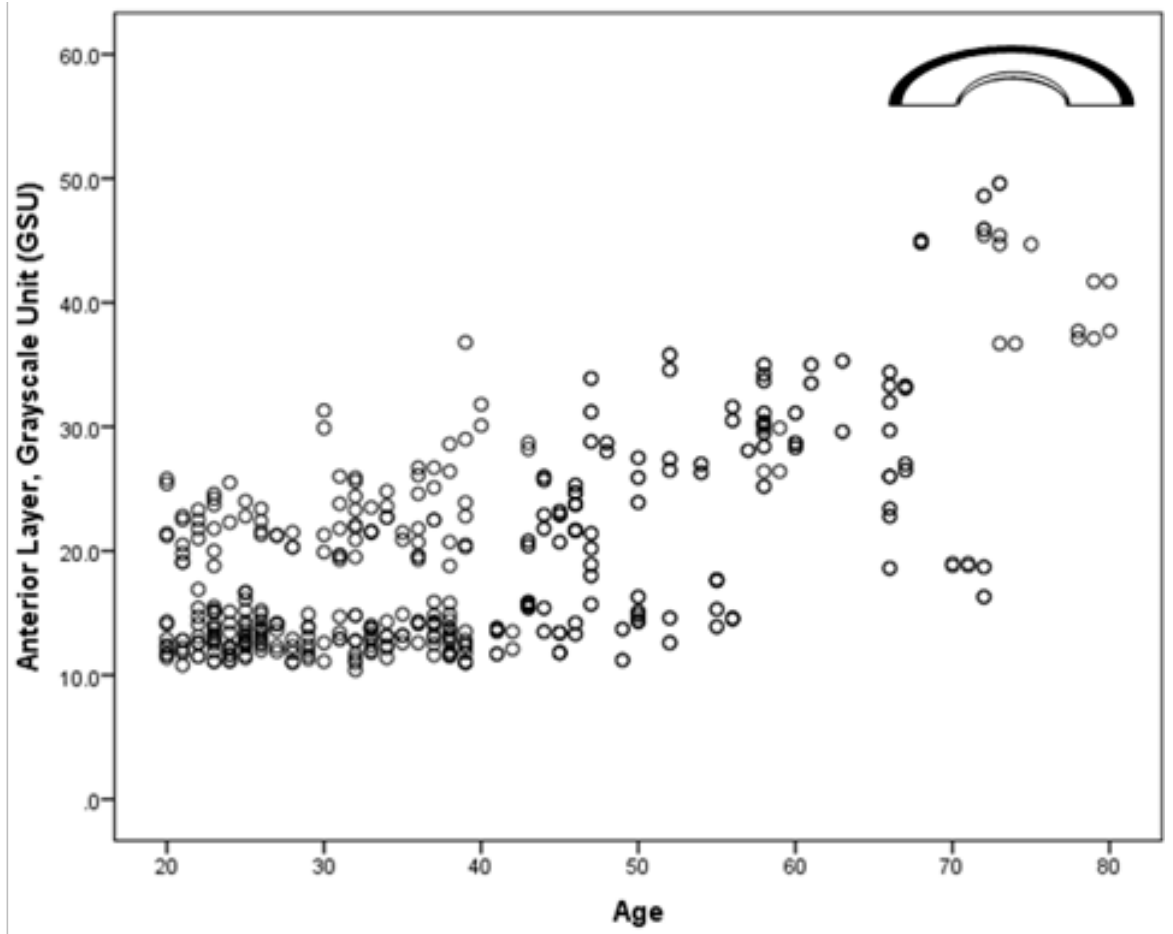

Figure 6 Corneal densitometry Subdivided by Surface Area; $* *$ Significant $p=0.015$; ***Highly Significant $p<0.001$; $p$ value obtained from independent $t$ test.

When cornea is evaluated by depth, the backscattering was higher from the anterior layer (20.6 $\pm 8.52 \mathrm{GSU})$ significantly higher than central (13.6 $\pm 5.17 \mathrm{GSU})$ and posterior layers (11.7 $\pm 3.99 \mathrm{GSU})$ with $\mathrm{p}<0.001$ (Figures 7-12). Significant correlation between age and corneal densitometry was found with pearson correlation $(\mathrm{r}=0.677$, $\mathrm{p}<0.001)$. Correlation significantly increases from central zone to limbal zone with age $(\mathrm{p}<0.001)$; pearson correlation $0-2 \mathrm{~mm}$ zone $\mathrm{r}=$ $0.46,2-6 \mathrm{~mm}$ zone $\mathrm{r}=0.55,6-10 \mathrm{~mm}$ zone $\mathrm{r}=0.72$, and $10-12 \mathrm{~mm}$ zone $\mathrm{r}=0.61$. Similarly, when cornea is subdivided by layers significant correlation between densitometry was found with age $(p<0.001)$; anterior $\mathrm{r}=67$, Central layer $\mathrm{r}=0.68$ and posterior layer $\mathrm{r}=0.66$. Range of corneal densitometry depending upon age is shown in Table 1 . 


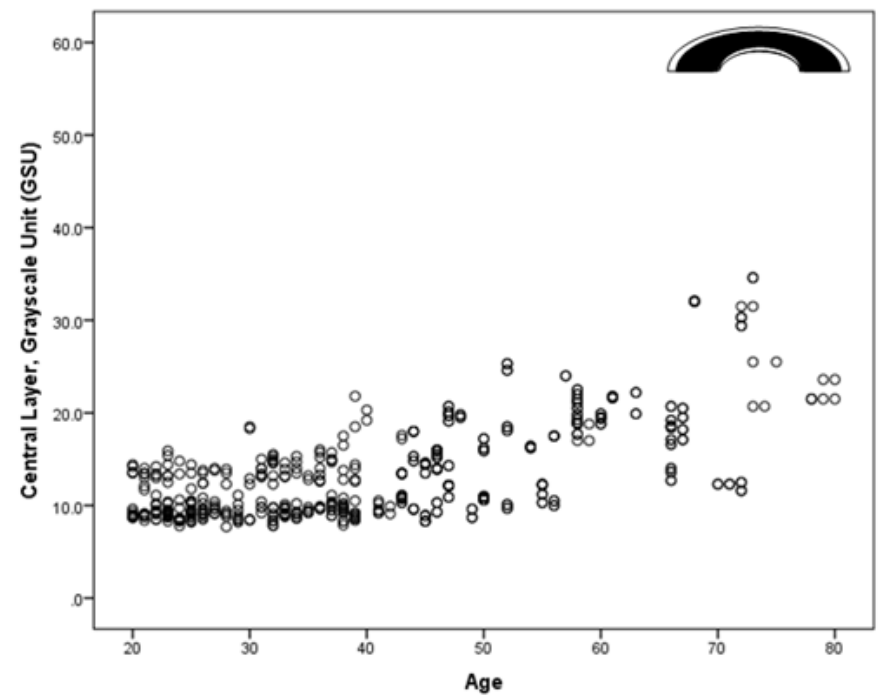

Figure 7 Corneal densitometry Subdivided by Corneal Depth; ***Highly Significant $\mathrm{p}<0.00$ I; $\mathrm{p}$ value obtained from independent $\mathrm{t}$ test.

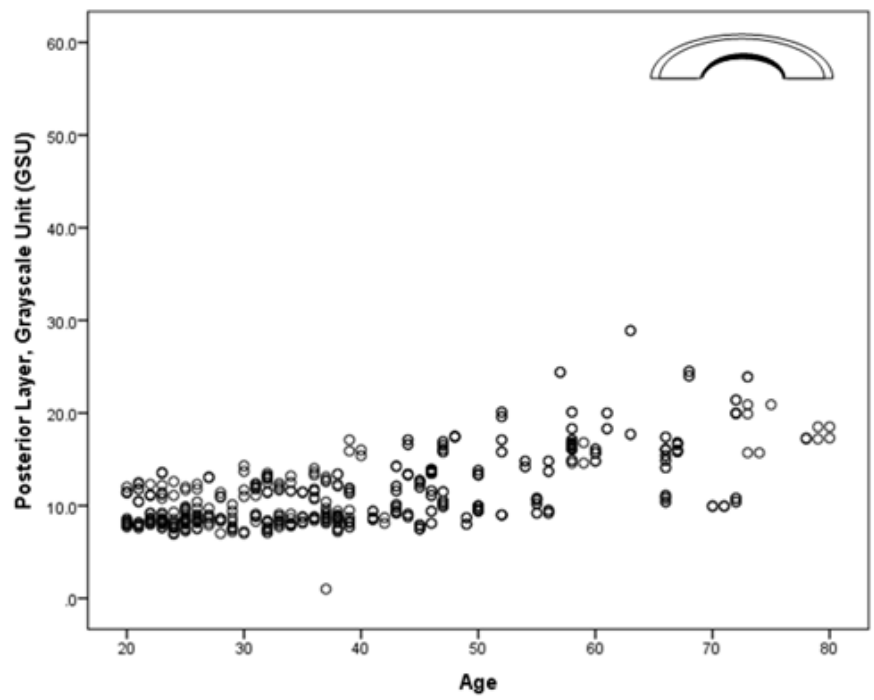

Figure 8 Linear Regression model; corneal densitometry; anterior layer plotted against age.

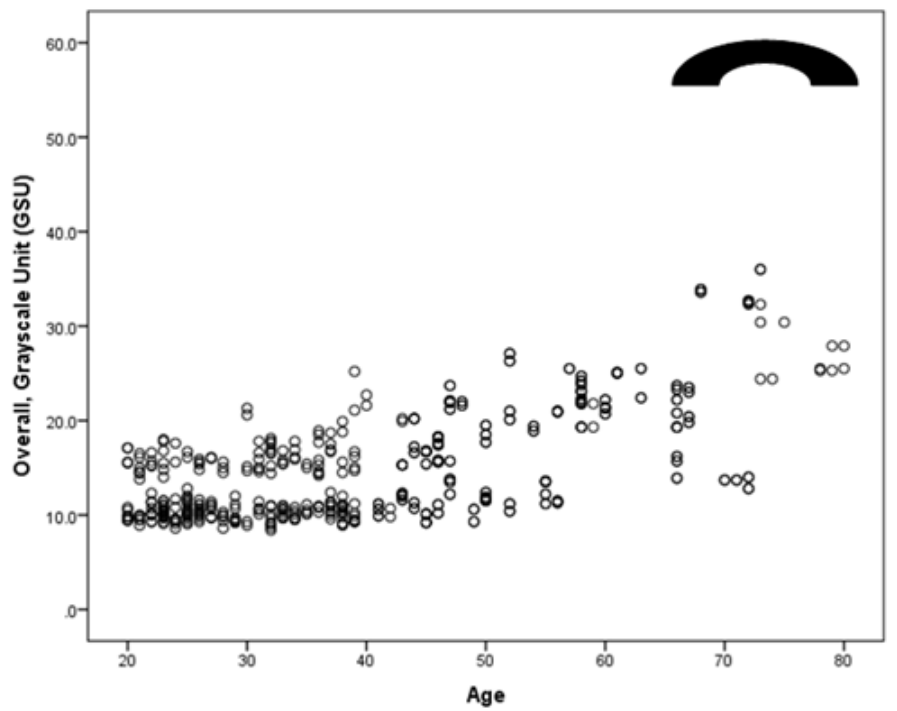

Figure 9 Linear Regression model; corneal densitometry; central layer plotted against age.

Citation: Asrar A, Ikram B, Khan H, et al. Normal values of corneal optical densitometry using pentacam scheimpflug camera. Adv Ophthalmol Vis Syst. 2016;5(I):202-209. DOI: 10.15406/aovs.2016.05.00I42 

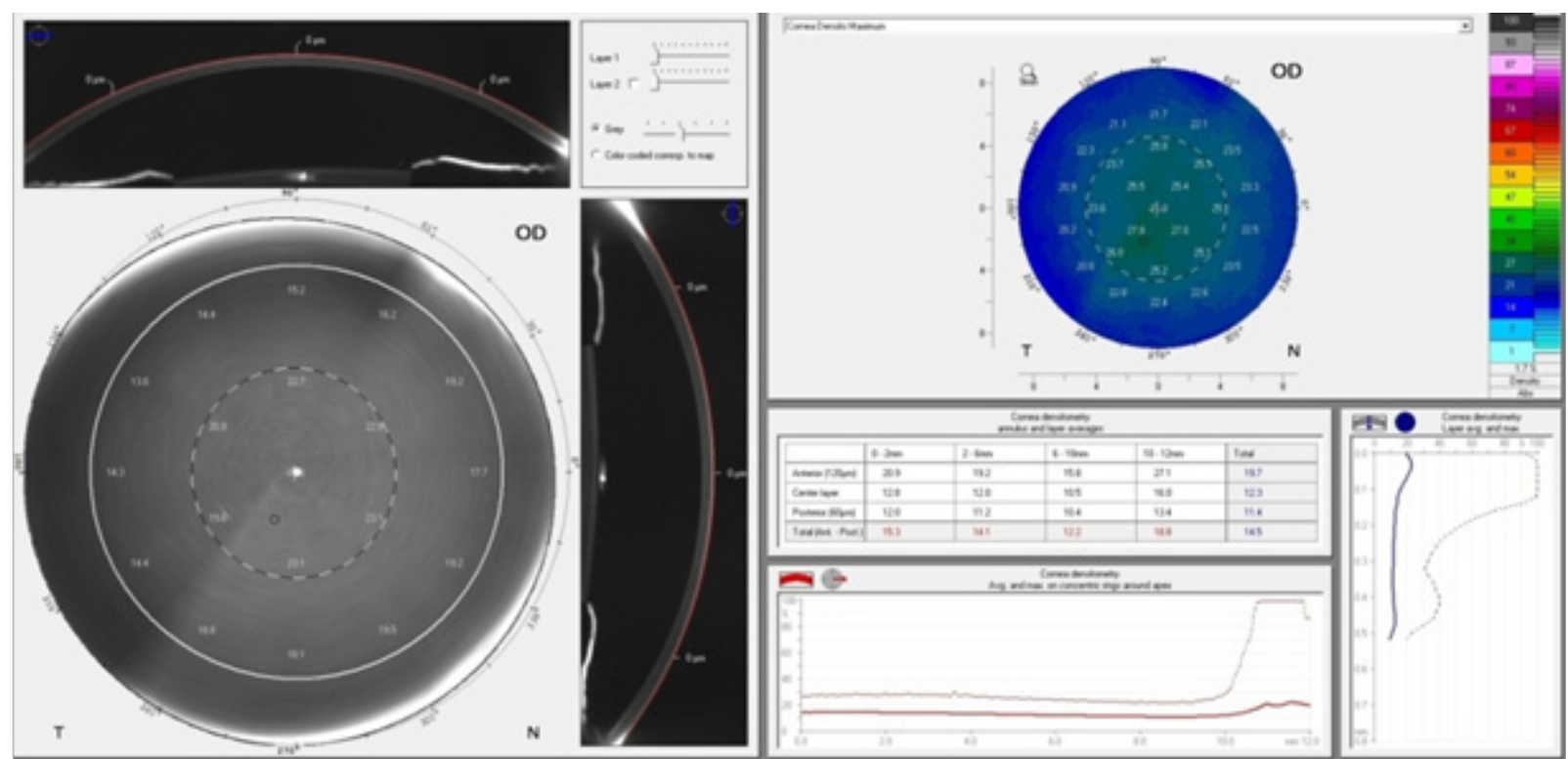

Figure 10 Linear Regression model; corneal densitometry; posterior layer plotted against age.

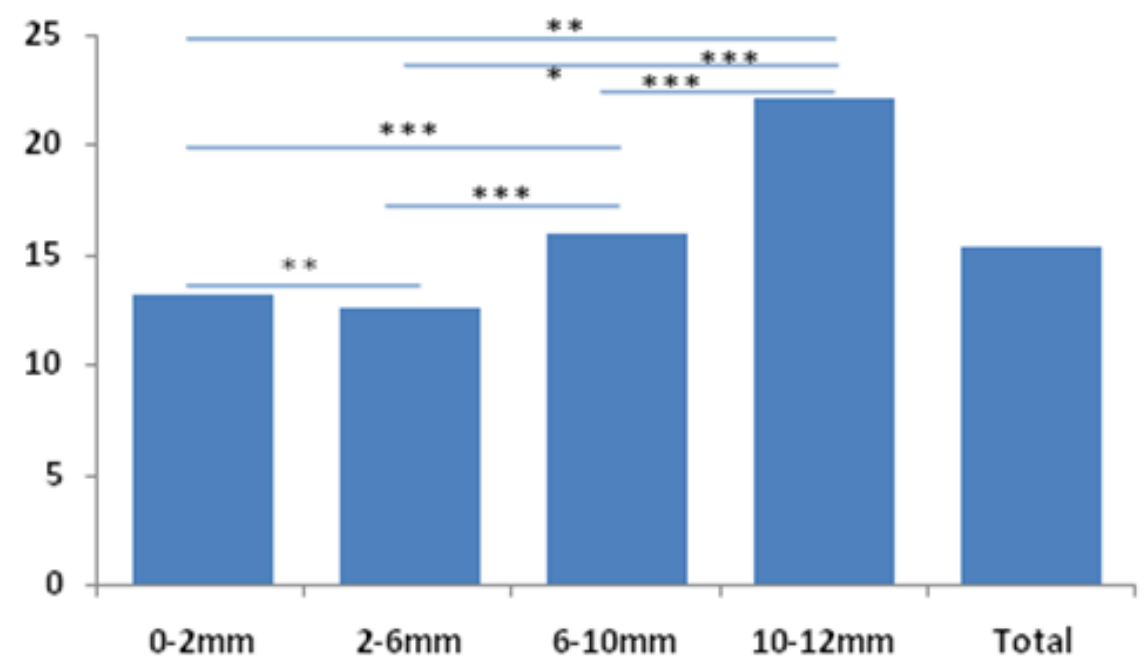

Figure I I Linear Regression model; corneal densitometry plotted against age.

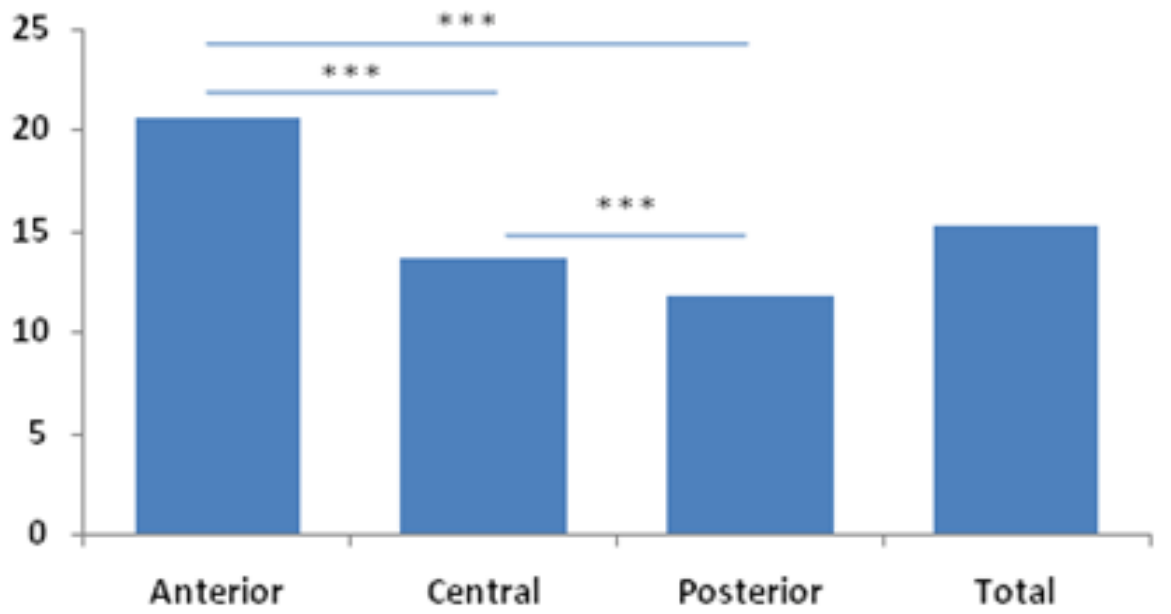

Figure 12 Corneal densitometry assessment; Screen data output. 
Table I All densitometry values are expressed in Grayscale unit (GSU)

\begin{tabular}{lllllll}
\hline Age group & $\mathbf{2 0 - 3 0}$ & $\mathbf{3 0 - 4 0}$ & $\mathbf{4 0 - 5 0}$ & $\mathbf{5 0 - 6 0}$ & $\mathbf{6 0 - 7 0}$ & $\mathbf{7 0 - 8 0}$ \\
\hline Number $(\mathrm{n})$ & 132 & 118 & 94 & 74 & 46 & 26 \\
Age mean \pm SD years & $24.1 \pm 2.56$ & $34.9 \pm 2.86$ & $45.0 \pm 2.11$ & $54.5 \pm 3.19$ & $64.6 \pm 2.82$ & $73.8 \pm 3.13$ \\
$0-2 \mathrm{~mm}$ & $11.2 \pm 2.92$ & $12.4 \pm 3.51$ & $13.2 \pm 3.40$ & $14.4 \pm 3.81$ & $17.8 \pm 2.52$ & $15.1 \pm 3.56$ \\
$2-6 \mathrm{~mm}$ & $10.5 \pm 2.45$ & $11.6 \pm 3.02$ & $12.3 \pm 2.93$ & $14.1 \pm 3.67$ & $16.9 \pm 3.08$ & $16.4 \pm 4.25$ \\
6- $10 \mathrm{~mm}$ & $10.2 \pm 2.35$ & $11.9 \pm 3.82$ & $15.4 \pm 5.67$ & $20.8 \pm 7.40$ & $26.4 \pm 7.44$ & $33.9 \pm 14.6$ \\
$10-12 \mathrm{~mm}$ & $17.2 \pm 4.66$ & $18.8 \pm 6.08$ & $22.8 \pm 7.34$ & $25.8 \pm 7.43$ & $29.9 \pm 7.46$ & $34.3 \pm 9.84$ \\
Anterior Layer $(160 \mu \mathrm{m})$ & $15.3 \pm 4.17$ & $17.4 \pm 5.66$ & $20.1 \pm 6.09$ & $24.5 \pm 7.50$ & $30.7 \pm 6.11$ & $35.4 \pm 12.36$ \\
Central Layer & $10.3 \pm 2.04$ & $11.5 \pm 2.89$ & $13.5 \pm 3.78$ & $16.4 \pm 4.69$ & $19.7 \pm 4.56$ & $22.1 \pm 7.88$ \\
Posterior $(60 \mu \mathrm{m})$ & $9.2 \pm 1.62$ & $10.0 \pm 2.36$ & $11.8 \pm 3.07$ & $14.1 \pm 3.87$ & $16.8 \pm 4.23$ & $16.6 \pm 4.76$ \\
Total Area & $11.6 \pm 2.58$ & $12.9 \pm 3.57$ & $15.2 \pm 4.31$ & $18.3 \pm 5.22$ & $22.3 \pm 4.61$ & $24.7 \pm 8.26$ \\
\hline
\end{tabular}

\section{Discussion}

The advancement of Pentacam Scheimpflug imaging system has made corneal tissues evaluation effortless with valid and reproducible results. ${ }^{9,10}$ It provides precise data of anatomical features of anterior chamber such as corneal topography, corneal densitometry and lens densitometry meticulously, with minimal user dependent. ${ }^{11}$ The corneal transparency is maintained by uniform alignment, size and spacing of collagen fibrils. Corneal densitometry provides information about corneal clarity and thus an indication of cornea health. Densitometry is expressed in grayscale unit from 0 to $100 ; 0$ means minimum backscattering of light (no clouding) and 100 means maximum backward scattering of light (opaque). ${ }^{12}$ An example of the data output is shown in figure 10. The current study represented the normal values for corneal densitometry in different age groups.

The maximal reflection of light was observed at anterior chamber $(120 \mu \mathrm{m})$ of cornea. This may be due to change of index i.e. from air to tear film and tear film to cornea interface. ${ }^{13}$ Lowest backscattering was observed in posterior $(60 \mu \mathrm{m})$ layer of cornea; where the change of refractive index is minor due to change in cell nuclei and nerves. Arrangement and organization order of corneal lamellea is at higher extent in posterior than anterior layers of cornea. ${ }^{14}$ Thus for optically transparent cornea, maximum light scattering occurs predominantly from anterior $120 \mu \mathrm{m}$ of cornea.

Previously, some literatures ${ }^{2,15}$ reported significantly increase of corneal density with age and some reported contradictory findings. ${ }^{4,16,17}$ However, this study observed a significant increase in corneal density of about 2-3 GSU with each increment of a decade of age. It was noted that density adjacent to limbal zone increased at much higher rate than the central zone $(0-6 \mathrm{~mm})$. This significant increase represented progressive age related changes in cornea such as arcus senilis, vogt's white limbal gridle, farinata etc. These degenerative but benign conditions are common in elderly and thus not considered as exclusion criteria for the study. ${ }^{18,19}$

The current study provided the range of normal values of corneal density in a large cohort. In practice, the reported values can be compared quantitatively and backscattering can be observed along corneal layers and surface to find out the extent of corneal haze in conditions such corneal dystrophies, infectious keratitis, keratoconus, after corneal grafting and post-refractive surgeries. The study added a large group of Asians, to the best of our knowledge this is the first study to report normal values of corneal densitometry on Asian cornea. Previous studies were done with Caucasians ${ }^{20}$ and Chinese Participants. ${ }^{21}$ Limitation of this study was small number of participants in groups' age above 60 . Reason due to most of the patients had had cataract extraction in this age, an exclusion criteria for this study.

\section{Conclusion}

With automated system of Pentacam Scheimpflug device corneal densitometry can be analyzed objectively in short duration of time. The study imparted a standardized values for corneal densitometry; subdividing the cornea on the basis of surface area and layer. Significant increase of corneal densitometry with age was observed. This study provided a platform for future research and facilitates the use of this knowledge in routine clinical practice.

\section{Acknowledgments}

None.

\section{Funding}

None.

\section{Conflicts of interest}

The authors declare there is no conflict of interests.

\section{References}

1. Freegard TJ. The physical basis of transparency of the normal cornea. Eye (Lond). 1997;11(Pt 4):465-471.

2. Olsen T. Light scattering from the human cornea. Invest Ophthalmol Vis Sci. 1982;23(1):81-86.

3. Braunstein R, Jain S, McCally RL, et al. Objective measurement of corneal light scattering after excimer laser keratectomy. Ophthalmology. 1996;103(3):439-443. 
4. Patel SV, Winter EJ, McLaren JW, et al. Objective measurement of backscattered light from the anterior and posterior cornea in vivo. Invest Ophthalmol Vis Sci. 2007;48(1):166-172.

5. Wang J, Simpson TL, Fonn D. Objective measurements of corneal lightbackscatter during corneal swelling by optical coherence tomography. Invest Ophthalmol Vis Sci. 2004;45(10):3493-3498.

6. Wegener A, Laser-Junga H. Photography of the anterior eye segment according to Scheimpflug's principle: options and limitations-a review. Clin Exp Ophthalmol. 2009;37(1):144-154.

7. Lerman S, Hockwin O. Automated biometry and densitography of anterior segment of the eye. Graefes Arch Clin Exp Ophthalmol. $1985 ; 223(3): 121-129$.

8. Patel SV, McLaren JW, Hodge DO, et al. The effect of corneal light scatter on vision after penetrating keratoplasty. Am J Ophthalmol. 2008;146(6):913-919.

9. Shankar H, Taranath D, Santhirathelagan CT, et al. Repeatability of corneal first-surface wavefront aberrations measured with Pentacam corneal topography. J Cataract Refract Surg. 2008;34(5):727-734.

10. Shankar H, Taranath D, Santhirathelagan CT, et al. Anterior segment biometry with the Pentacam: comprehensive assessment of repeatability of automated measurements. J Cataract Refract Surg. 2008;34(1):103113

11. Oculus. Pentacam instruction manual. Wetzlar, Germany: Oculus 2003:5-43.
12. Cho YK, Chang HS, La TY, et al. Anterior segment parameters using Pentacam and prediction of corneal endothelial cell loss after cataract surgery. Korean J Ophthalmol. 2010;24(5):284-290.

13. Maurice DM. The structure and transparency of the cornea. $J$ Physiol. 1957;136(2):263-286.

14. O'Donnell C, Wolffsohn JS. Grading of corneal transparency. Cont Lens Anterior Eye. 2004;27(4):161-170.

15. Hillenaar T, Cals RH, Eilers PH, et al. Normative database for corneal backscatter analysis by in vivo confocal microscopy. Invest Ophthalmol Vis Sci. 2011;52(10):7274-7281.

16. Smith G, Brown NAP, Shun-Shin GA. Light scatter from the central human cornea. Eye. 1990;4(Pt 4):584-588.

17. Otri A, Fares U, Al-Aqaba MA, et al. Corneal densitometry as an indicator of corneal health. Ophthalmology. 2012;119(3):501-508.

18. Forstot S. Marginal corneal degenerations. Int Ophthalmol Clin. 1984;24(2):93-106.

19. Farragher R, Mulholland B, Tuft SJ, et al. Aging and the cornea. $B r J$ Ophthalmol. 1997;81(10):814-817.

20. N'1 Dhubhghaill S, Rozema JJ, Jongenelen S, et al. Normative values for corneal densitometry analysis by Scheimpflug optical assessment. Invest Ophthalmol Vis Sci. 2014;55(1):162-168.

21. Wu Z, Wang Y, Zhang L, et al. Distribution of corneal densitometry and its correlation with ocular stray light in healthy eyes. Zhonghua Yan Ke Za Zhi. 2014;50(1):20-26. 